\title{
A cultura jurídica como (arte)fato: uma pontuação historiográfica*
}

\author{
The legal culture as (arti)fact: an historiographical remark
}

GROSSI, Paolo. A ordem jurídica medieval. Tradução de Denise Rossatto Agostinetti. São Paulo: WMF Martins Fontes, 2014. 344p.

\section{Rogerio Ribeiro Tostes}

rogerio.tostes@gmail.com

Doutorando em História

Universidade de Lleida

Consolidated Medieval Studies Research Group "Space, Power and Culture"

Plaça de Víctor Siurana, 1 - 25003 - Lleida

Espanha

Palavras-chave

História das instituições; História medieval; História Cultural.

\section{Keywords}

History of institutions; Medieval History; Cultural History. 
Afinal, sai à prensa a tradução brasileira do livro de Paolo Grossi, o eminente historiador do direito e atual presidente do tribunal constitucional da Itália. Ela vem exatamente vinte anos depois do aparecimento de sua primeira edição italiana, então publicada pela casa editorial Laterza. ${ }^{1}$ Não seria exagero acrescentar que este trabalho já era esperado pelo pequeno e cultivado público brasileiro de historiadores do direito, componentes de uma historiografia jovem que, não por acaso, recebeu os primeiros rudimentos dos historiadores italianos e se autointitulou herdeira da escola florentina.

Tal recepção, consumada agora pela existência desse guia introdutório ao direito medieval - a que o autor reluta chamar de "manual" -, deve ajudar a disseminar no país uma série de linhas-mestras sobre o pensamento jurídico tout cour e não apenas sobre o medieval. Mas por que isso acontece aqui, já que se trata de um livro que desde o seu aparecimento coincidiu com os debates sobre a natureza e a rigorosa demarcação do direito medieval? Poderíamos indicar algumas possibilidades. Primeiro, que esse livro vem para atender à demanda de um público que não procura nenhum estudo metódico do "direito medieval", entendendo-o, se quisermos, como objeto autônomo de conhecimento histórico, mas que espera tirar dele o seu pacote conceitual, aberto às variantes de uma chamada cultura jurídica.

Depois, porque esse mesmo público, herdeiro de um projeto jurídico-político claro, pretende iniciar aqui uma disciplina crítica, a "história do direito", na qual tende a construir suas bases de justificação pelo revisionismo das categorias 178 hegemônicas vindas do Iluminismo positivista (GROSSI 2007). Estaríamos quase diante de uma transposição de cenários, que troca as latitudes europeias para buscar em terra brasilis as suas novas formas de compreensão do direito. Provando dessa forma - mesmo a fortiori - que o direito se dá num "significado essencialmente ontológico" e, como tal, "penetra nas origens mais profundas de uma civilização" (GROSSI 2014, p. 6) que, como a nossa, mantém alguma visão da continuidade a partir das experiências colonial e pós-independência com uma vertente própria de cultura(s) jurídica(s) (FONSECA 2004, p. 61-73). $E$, também, porque, como afirmou mais de um aluno dessa escola, esta é a parcela da civilização ocidental que floresceu seus ramos nas jovens e híbridas culturas jurídicas das Américas.

Essa relação entre o livro e a sua recepção, distantes no tempo e no espaço por contextos intelectuais que não se devem misturar, cria um certo desconforto quando nos damos conta de algumas discrepâncias de conteúdo. Entretanto, por ora, deixemos esse tópico em suspenso, já que a questão da recepção do livro, não apenas no Brasil, como em outros países europeus (ASCHERI 1996, p. 965973; TOMÁS Y VALIENTE 1996, p. 1-2), merece mais tempo para que se avalie as sequências - reais ou imaginárias - de sua genealogia hermenêutica (CONTE 2002, p. 1593-1612). Queda-nos, entretanto, o propósito teórico daquelas tais continuidades/rupturas que preside tanto a obra do historiador italiano quanto a de seus continuadores no aquém e além continente.

$\overline{1}$ Tomada da última reimpressão italiana de 2006. 
Apesar do cuidado de Grossi a evitar projeções continuístas em sua interpretação da história do direito, negando enxergar o medievo como um estágio preparatório da modernidade, foi sob esse pugilato entre medievo e modernidade que se consagraram importantes ideias-chave da produção grossiana. Vemos, aliás, que elas são repetidas em monografias e ensaios que falam do ordenamento jurídico ou dos temas da experiência e cultura jurídicas. Elas também se repetem na recuperação das formas institucionais de unidade/ pluralidade desses ordenamentos, onde há sempre uma herança da civilização medieval encadeada pelo direito.

Por aí, há que se sublinhar certos pontos na proposta pensada por Grossi.

Sua explicação parte da fragmentação jurídica produzida no período tardoimperial romano sobre o continente europeu, então dominado por diversas comunidades bárbaras (sécs. III-IV). É desse cruzamento de formas institucionais romano-bárbaras que as suas sociedades enraizaram suas culturas jurídicas locais. (Ou seja, essa base de explicação é a mesma que segue o estilo dos Volksrechte, segundo uma noção que os jus-historiadores italianos receberam dos germanistas do século XIX e mantiveram quase inalterada, ainda hoje, em seus manuais de história institucional.)

Sobre os restos dessa civilização irromperia uma outra, a dos carolíngios, em que ascendia um novo momento para o direito romano-bárbaro. Esse direito, que se mostrou um tipo de direito elaborado pela prática cotidiana do homem comum a partir dos séculos finais da época alto-medieval, transformou o costume em fonte e em base de eficácia jurídica. Ponto importante que, segundo Grossi, nos ensina algo sobre o papel do direito na vida do homem e sua relação espontânea na escalada das sociedades ocidentais.

Essa particular presença do costume nos sedimentos de um direito que se projeta do Tardo Antigo ao Alto Medievo justificará o vínculo mantido depois em todas as sociedades baixo-medievais ( $v$. cap. 4). Um vínculo aperfeiçoado pela sistematização do direito comum e suas formas sapienciais, chegando à cristalização de seus últimos estágios durante a escolástica, através das teorizações corporativas que idealizavam um todo universal da cristandade (caps. 6-9).

Se olhados por alto, esses elementos compõem para o historiador italiano o pleno sentido da mentalidade jurídica medieval, que é em sua forma completa uma unitate ordinis (GIERKE 1958, p. 8-9), uma tópica que ele toma dos filósofos medievais e usa como chiave di volta para completar seu ensaio. É aí mesmo que o direito se mostra um produto elementar, podendo ser uma nova categoria do ser que completa a experiência histórica do devir humano, um devir que deve ser apreendido pela dimensão ôntica do universo natural (GROSSI 2014, p. 44).

Há que se admitir, então, que estamos diante de uma síntese, de uma grande obra, na qual se recolhe o esforço de uma proposta muito mais ambiciosa que aquela que seu autor assumiu realizar a partir do prefácio. Trata-se ainda de uma proposta de época, em que emerge um cruzamento de gerações consagradas à história jurídica. Por dentro dessa proposta há uma parte do trabalho que define seu objetivo em reunir influências nem sempre conciliáveis, como as que foram adquiridas de autores como Santi Romano, Otto Brunner, Francesco 
Calasso ou Carl Schmitt. Isso tudo além de uma constante preocupação em dialogar com as inovações dos Annales, num repasse que vai da história social ao estudo das mentalidades, e contra a história do poder e das instituições, para enfim redimir a história do direito de seu tradicional isolamento frente às demais especialidades da história geral (LE GOFF 1986, p. 23-63).

Entretanto, foi através das pontes criadas entre elas, aparando aqui e ali seus "excessos", que o autor radicalizou a crítica - bastante original nesse ponto - feita ao Estado moderno, indo ao medievo para livrar a contemporaneidade do "estatalismo psicológico" (GROSSI 2014, p. 43) em que a sociedade contemporânea acabou por cair doente. Para se contrapor ao monismo do direito pelo Estado, detentor de algo que chamou "absolutismo jurídico", Grossi foi escavar na Idade Média uma alternativa vivente ou um outro meio possível, segundo a genealogia empenhada por ele e seus continuadores. É desse marco em diante que se sacaram as conclusões a respeito de um sistema jurídico histórico que brotou de uma necessidade antropológica, uma necessidade que ele dá como possível pelo advento de um direito sem Estado (GROSSI 1996, p. 267-284).

É aqui, suponho, que seu trabalho passa a merecer algumas avaliações de fundo.

O primeiro senão, e talvez o mais sério, resulta nessa amálgama criada por Grossi entre o "sistema-ordenamento" e a fonte derivada da "experiência jurídica". Trata-se de um argumento usado para descartar a teoria do poder e o legalismo estatalista, os mesmos que representam para ele os agentes deformadores da normalidade da vida. É como se o Estado de direito fosse uma força anti-histórica que age contrariamente à espontaneidade praxiológica do direito. Por isso ele deve ser combatido na reinterpretação de uma genealogia da cultura jurídica ocidental (ASCHERI 1996, p. 969).

O problema - se assim podemos chamar o que vem a seguir - é que uma tal investigação genealógica acaba contaminada pelo que há de mais moderno no método de compreensão das instituições. Pois, enquanto a vivência "prática dos medievais" pretende re-ensinar o jurista moderno a enxergar a essência do direito pela "experiência" - que "remete à vida do direito, ao fato de que o direito consiste numa dimensão da existência" (GROSSI 2014, p. 31) -; é esse "ordenamento sistêmico" do direito vindo dos antigos que acaba transformado pela busca essencializante do ordo iuris, que faz dele uma teoria tão abstrata e universalista quanto a racionalidade moderna que ele acabara de rechaçar.

Daí que fundir o projeto do jurista Santi Romano para interpretar a existência dos direitos locais à maneira de um sistema iuris (ROMANO 2008) ao lado de uma noção de costume como "constituição duradoura" (GROSSI 2014, p. 44), no sentido empregado por Carl Schmitt e extensivamente ao modelo histórico de Fritz Kern (KERN 2013), acaba por criar um estranho contrassenso entre teoria e prática, e um problema adicional sobre a sua pretensa inserção historiográfica.

Vemos, por exemplo, que em Paolo Grossi toda sua evocação à Verfassungslehre ("Teoria da Constituição") é quase simultânea à negação da teoria do poder (GROSSI 2014, p. 69-72), um valor que sem dúvida alguma ocupa um lugar insubstituível na compreensão schmittiana do direito como 
imanência política (IGLESIA 2006). É justamente por isso que ela não deveria ser separada da mesma ideia de experiência que Schmitt definiu nos trabalhos de sua fase clássica, na época do entre-guerras (SCHMITT 2005, p. 23-63). Da mesma maneira que a intenção sustentada por Grossi de qualificar o direito medieval como sistema jurídico de ordenamentos plurais, in extenso, só será possível pela idealização de uma coexistência sob o direito comum, na qual as dissonâncias dos ordenamentos locais fecham uma realidade harmônica em que se cabem "posizione tanto dialettica con i varii iura propria" (GROSSI 2006, p. 227). Ao montante de tudo, parece ainda mais grave que isso consista, para ele, na verdadeira via que leva à autenticidade da história.

A proposta levantada desde as primeiras páginas desse livro vai, pouco a pouco, se desvirtuando de sua meta, aquela mesma meta que pretendia retomar a "especificidade da experiência jurídica medieval". Pois logo que o autor dá por acabado o seu objetivo de entender a pluralidade dessas experiências no tempo e no espaço medieval, vê-se que cada especificidade descoberta vai se transformando num conjunto abstrato, estranho à mesma prática que pretendera revelar, reduzindo todo o panorama das realidades jurídicas medievais a uma perpetua variatio da essência universal, a partir da qual ainda se pode falar de uma civilização:

[...] em suma, um patrimônio de princípios, noções e expedientes universais porque fundados na razoabilidade, universais porque expressão de uma civilização jurídica experimentada pelos séculos; como tais, universalmente presentes e vigentes em todos os tempos e em todos os lugares. [...] Tratava-se efetivamente de um patrimônio de toda a humanidade civilizada, fundada na razão (GROSSI 2014, p. 285).

A segunda questão é a relação com o Estado, onde se aprofunda uma interpretação do passado como um jogo de contrastes, um jogo que se empenha em confrontar sua figura no tempo como tentativa de desfazê-lo entre os seus artifícios de formalismo; vem, assim, o esforço de questionar a ideologia tecnocrata do legalismo, implantada há duzentos e tantos anos pelo reformismo do Estado burguês, numa crítica pesada e às vezes caricatural do legalismo e do poder estatal. O que era possível porque, para ele, não existiu um centro irradiante de autoridade nem uma Lei como centro de vigência dos ordenamentos. Bastavam aos juristas medievais o conhecimento do costume, da equitas ruda e de uma técnica interpretativa perspicaz. Por mais presentes que fossem o texto da Lex e de suas ficções, todo seu mecanismo operacional fora materializado por técnicas muito particulares, das quais se entrevê principalmente a interpretatio medieval, que apenas admitia os textos justinianeos quando submetidos ao crivo dos glosadores (CALASSO 1951, p. 3-30). Assim, se empobrece o referencial da Lex scripta (Lex generalis omnium) que conferiu, uma vez filtrada pela glosa acursiana, o cerne de toda a racionalidade das práticas e das chaves de representação do fenômeno jurídico medieval.

Outro ponto pertinente está em sua revisão da obra de Francesco Calasso e o afastamento de um estado em função do fraco caráter legislativo ensaiado 
nos sistemas monárquicos; um revisionismo que não foi capaz de superar as generalizações calassianas dos fenômenos jurídicos experimentados na Europa, supondo, basicamente, que eles coincidissem com as formas institucionais aparecidas na Itália medieval ${ }^{2}$. A relutância de Grossi em aceitar o estado medieval poderia servir para questionar sua aceitação - questionável também, sobretudo se pensada a partir de alguns termos que ele mesmo empregou implicitamente - a respeito do Império Romano (ou "Estado Imperial"?) e de outras formas históricas de organização política.

Mas é no seu rechaço à ideia de um Poder (ascendente ou descendente, não importa) que temos o aspecto mais estimulante e controverso de todo o livro. Em seu "desinteresse" pelo poder temos aqui uma questão delicada, já que com ela se deve levar em conta alguns debates implícitos na interpretação grossiana (PACHECO 1995, p. 795). Em sua busca pela effettività dos ordenamentos medievais, o autor está convencido de que a ausência dos núcleos de comando centralizado estavam ligados à falta de atitude do príncipe diante do primado da lei e, por aí, explicava-se a desvinculação mais ou menos genérica do político sobre o jurídico. Afinal, esse poder político é por definição incompleto, portanto incapaz de subabastecer a eficácia do direito. ${ }^{3}$

Se na obra de Grossi nos vemos às voltas com "un diritto che non è voce del potere" ("un direito que não é a voz do poder"), temos que nos perguntar o seu porquê. Para chegar a compreender isso, há que se precaver para o seguinte detalhe: ele não nega a existência do poder sub essentia primaria na criação do direito. O que ele parece rejeitar é a mundanidade secular do poder, esse poder esvaziado, destituído da aura mística do ius canonicum, que solapou as bases da autoridade política e que parece presidir à força as sociedades humanas ergo: um poder reduzido ao mero império da lei.

Assim, pela meta-humanidade invocada no ordenamento jurídico medieval, Grossi sugere que a razão moderna vá olhar aos antigos para descobrir o que foi deixado no caminho. Neste aspecto, ainda que de uma maneira pouco prática ou realística, ele mantém sua dívida com Schmitt: o poder só é verdadeiro se for uma força derivada da transcendência teísta.

Esse poder transcendente, que, segundo o autor, não reside em um príncipe mas se dilui em zonas de transferência entre um Acima e um Abaixo, ganha expressão nas relações múltiplas e harmônicas das sociedades corporativas (GROSSI 2014, p. 58-60). Com efeito, Grossi reforça muitas vezes o aspecto corporativo das sociedades medievais (aliás, outro artefato que ele herda da historiografia alemã) como chave para compreender a coexistência dos sistemas jurídicos e sua presença em um ordenamento coeso.

\footnotetext{
${ }^{2} \mathrm{Na}$ década de 1950, Alfonso Otero já rebatia as leituras de Calasso sobre a recepção do direito romano na península Ibérica, abrindo um debate que ainda encontra continuidade em alguns dos seus discípulos (OTERO 1964, p. 141-162; CALASSO 1954).

3 "entendendo por incompletude a carência de toda vocação totalizante do poder político, sua incapacidade de se apresentar como fato global e assimilador de todas as manifestações sociais, sua realização nos acontecimentos históricos medievais cobrindo apenas certas áreas das relações intersubjetivas e permitindo, em outras [...], a possibilidade de ingerências de poderes concorrentes [...]" (GROSSI 2014, p. 50).
} 
Até aí estamos bem; pois me parece sensato seguir um esquema interpretativo que rejeita servir-se de antessala para o individualismo moderno. Mas enquanto ele tiver que sustentar a coesão daquela mentalidade medieval à causa de "forças circulantes e operativas na sociedade", forças essas que nada têm da metáfora durkheimeana do "laço social" ou de qualquer explicação antropológica que o valha, mas repousam numa convicção pessoal sobre a "ontologia jurídica", então podemos questionar o caráter de análise histórica que o autor nos oferece. De fato não temos um manual, mas um tipo de ensaio historiográfico que tenta capturar a mentalidade jurídica au delà das usuais limitações do juridicismo, mas que no fim não supera a crença num direito histórico essencializante.

\section{Referências bibliográficas}

ASCHERI, Mario. Un ordine giuridico medievale per la realtà odierna?. Rivista trimestriale di diritto e procedura civile, v. 50, n. 3, p. 965-997, 1996.

CALASSO, Francesco. Introduzione al diritto comune. Saggio I: Tradizione e critica metodologica. Milano: Griuffrè, 1951.

CALASSO, Francesco. Medio evo del diritto. Le fonti, vol. I. Milano: Ed. Giuffrè, 1954.

CONTE, Emanuele. Droit médiévale. Un débat historiographique italien. Annales. Histoire, Science Sociale, v. 57, n. 6, p. 1593-1613, 2002.

FONSECA, Ricardo M. A cultura jurídica brasileira e a questão da codificação civil no século XIX, Revista da Faculdade de Direito, v. 41, p. 61-76, 2004.

GIERKE, Otto von. Political theories of the Middle Age. Boston: Beacon Paperback, 1958 [1868].

GROSSI, Paolo. Un diritto senza Stato. La nozione di autonomia come fondamento della costituzione giuridica medievale. Quaderni Fiorentini per la storia del diritto, v. 25, 1996, p. 267-284.

. L'ordine giuridico medievale. 12. ed. Roma/Bari: Laterza, 2006.

GROSSI, Paolo. Mitologias jurídicas da modernidade. 2. ed. Florianópolis: Fundação Boiteux, 2007.

IGLESIA FERREIRÓS, Aquilino. Recensión a 'Grossi, Paolo, Derecho, sociedad, Estado (Una recuperación para el derecho). Initium. Revista catalana d'Història del Dret, v. 11, p. 937-980, 2006.

KERN, Fritz. Derecho y Constitución en la Edad Media. Valencia: Kyrios, 2013 [1919].

LE GOFF, Jacques. Histoire Medievale et Histoire du Droit: um dialogue difficile. In: GROSSI, Paolo (org.). Storia sociale e dimensioni giuridica: strumenti d'indagine e ipotesi di lavoro. (Atti dell'Incontro di Studio. 
Firenze, 26-27 aprile 1985). Milano: Ed. Giuffrè, 1986, p. 23-63.

OTERO, Alfonso. Sobre la 'plenitudo potestatis' y los reinos hispánicos. Anuario de historia del derecho español, v. 34, p. 141-162, 1964.

PACHECO, Francisco L. Recensión de Paolo Grossi, L'ordine giuridico medievale. Bari, Editorial Laterza, 1995. Initium. Revista catalana d'Història del Dret, v. 2, p. 795-796, 1997.

ROMANO, Santi. O ordenamento jurídico: a construção da justiça administrativa. Florianópolis: Fundação Boiteux, 2008 [1917].

SCHMITT, Carl. Teología política, cuatro ensayos sobre la soberanía. Buenos Aires: Editorial Struthart, 2005.

TOMÁS Y VALIENTE, Francisco. Una experiência jurídica medieval: sobre 'L'ordine giuridico medievale', de Paolo Grossi. Saber leer, p. 1-2, v. 94, 1996. 